\title{
Colliders and Neutrinos
}

The Window into

Physics beyond the Standard Model 
This page intentionally left blank 


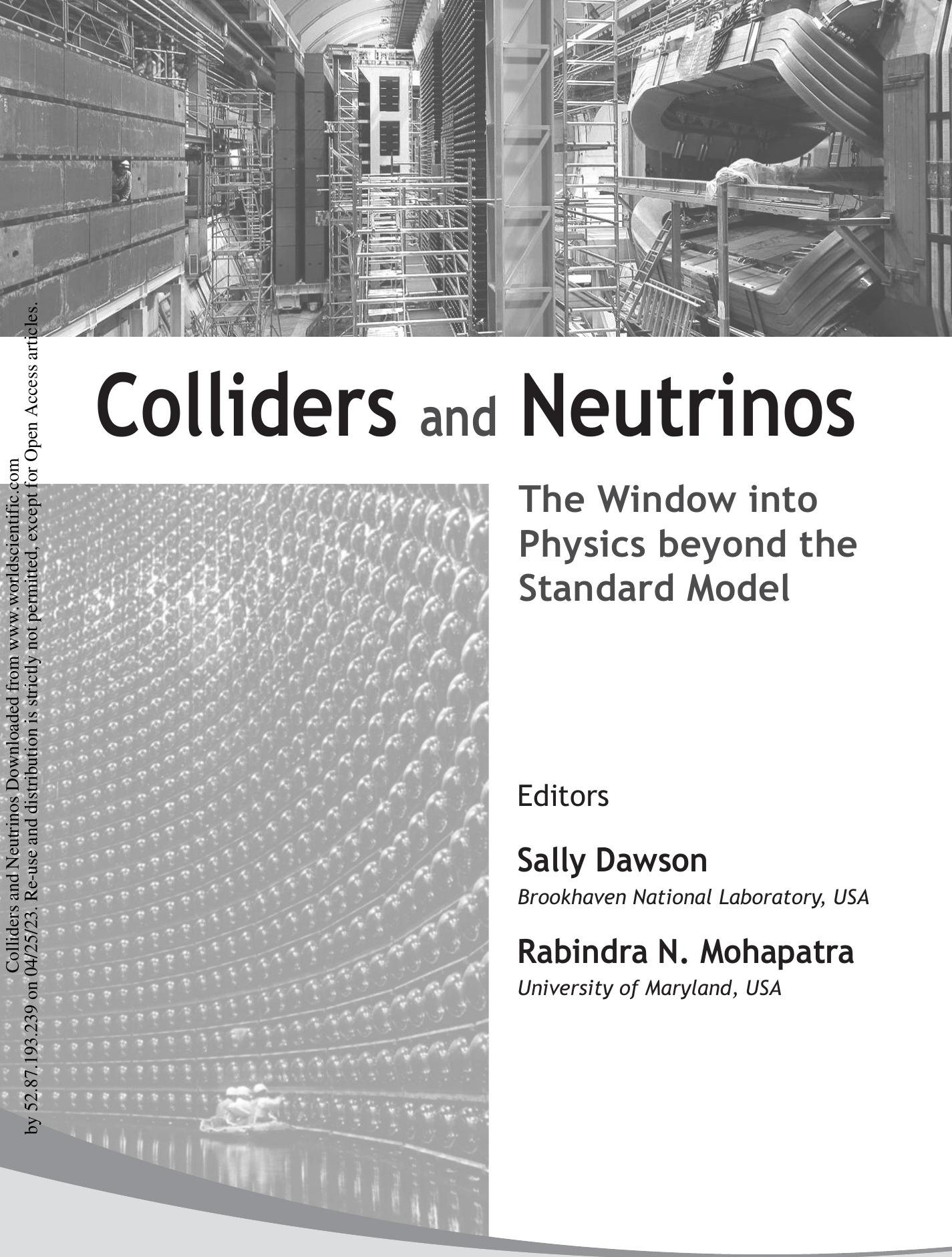

\section{Noworld Scientific}




\section{Published by}

World Scientific Publishing Co. Pte. Ltd.

5 Toh Tuck Link, Singapore 596224

USA office: 27 Warren Street, Suite 401-402, Hackensack, NJ 07601

UK office: 57 Shelton Street, Covent Garden, London WC2H 9HE

\section{British Library Cataloguing-in-Publication Data}

A catalogue record for this book is available from the British Library.

\section{COLLIDERS AND NEUTRINOS \\ The Window into Physics beyond the Standard Model \\ (TASI 2006)}

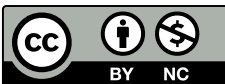

Open Access Publishing in Particle Physics

\section{Open Access funded by SCOAP ${ }^{3}$}

Copyright (c) 2022 The Editor(s) (if applicable) and The Author(s)

This ebook was converted to Open Access in 2022 through the sponsorship of SCOAP3, licensed under the terms of the Creative Commons Attribution-NonCommercial 4.0 International License (https://creativecommons.org/licenses/by-nc/4.0/), which permits use, sharing, adaptation, distribution and reproduction in any medium or format, as long as you give appropriate credit to the original author(s) and the source, provide a link to the Creative Commons license and is used for non-commercial purposes.

Copyright (C) 2008 by World Scientific Publishing Co. Pte. Ltd.

ISBN 978-981-281-925-3 (hardcover)

ISBN 978-981-281-926-0 (ebook for institutions)

ISBN 978-981-4470-62-9 (ebook for individuals)

For any available supplementary material, please visit

https://www.worldscientific.com/worldscibooks/10.1142/6912\#t=suppl 
2022 (c) The Author(s). This is an Open Access chapter published by World Scientific Publishing Company, licensed under the terms of the Creative Commons Attribution-NonCommercial 4.0 International License (CC BY-NC 4.0). https://doi.org/10.1142/9789812819260_fmatter

\section{Preface}

With many experimental undertakings around the corner such as the Large Hadron Collider, with many neutrino experiments already in the pipeline or under way and with aspirations for perhaps an International Linear Collider in not too distant future, the field of Particle Physics is poised to take a giant leap into unravelling the unknown world of new particles and forces in the coming decades and build on its success of the past four decades. Combined with the spectacular developments in the field of cosmology, which has perhaps already given us the standard model of the universe and begging for new ideas from particle theory for a deeper understanding of observations, the promise of major breakthroughs and deep insights have filled the air. Many exciting ideas such as supersymmetry, extra dimensions and grand unification are reaching a stage of maturity waiting to be tested. We may also learn about the true nature of the dark constituent of the universe, as well as about the happenings at the early moments of the Big Bang embodied in the ideas of inflation. These discoveries may also provide a better understanding of the formation of structure and evolution of stars and galaxies.

In order to prepare for this new era, the TASI summer school has always been structured to bring to $\mathrm{Ph}$. D. students in the US and abroad the latest ideas and information in a cogent and pedagogical manner, so as to build the intellectual base for tackling the new theoretical challenges that will emerge and are already emerging. The 2006 TASI school was charged with bringing the new phenomenological, cosmological and model building frontier to the students and researchers of tomorrow. With this in mind, we decided to focus on two main themes: Colliders and Neutrinos at the frontier of Physics and inviting experts in the related fields to lecture at the school. 


\section{Acknowledgments}

We are grateful to all the speakers for taking time out of their busy schedule to prepare lectures and interact with students and contribute to the success of the school. We are especially grateful to those who submitted the written version of the lectures that can be an invaluable educational resource for students both now and in future. We thank Susan Spika and Elizabeth Price for efficient secretarial assistance before and during TASI, Abdul Bachri and Sogee Spinner for organizing the student seminars, Erin DePree and Nicholas Setzer for designing and distributing the TASI06 tee-shirts and Thomas Degrand for organizing the hikes. We thank the National Science Foundation, the Department of Energy, and the University of Colorado for financial and material support. We are very grateful to Prof. K. T. Mahanthappa for superb organization and for being a wonderful host.

Sally Dawson

Rabindra N. Mohapatra 


\section{Contents}

Preface $\quad$ v

Extra Dimensions $\quad 1$

K. Agashe

The International Linear Collider

M. Battaglia

Astrophysical Aspects of Neutrinos

J. F. Beacom

Leptogenesis

M.-C. Chen

Neutrino Experiments

J. M. Conrad

String Theory, String Model-Building, and String

Phenomenology - A Practical Introduction

K. R. Dienes

Theoretical Aspects of Neutrino Masses and Mixings

R. N. Mohapatra

Searching for the Higgs Boson

D. Rainwater

$\mathrm{Z}^{\prime}$ Phenomenology and the LHC

T. G. Rizzo

Neutrinoless Double Beta Decay

P. Vogel

Supersymmetry in Elementary Particle Physics

M. E. Peskin 